\title{
OPTIMASI TUNGKU PELEBURAN LOGAM ALUMINIUM KAPASITAS 10 KG BERBAHAN BAKAR OLI BEKAS SKALA LABORATORIUM
}

\author{
Budi Istana, Abrar Ridwan, Ade Rilnanda \\ Jurusan Teknik Mesin Fakultas Teknik,Universitas Muhammadiyah Riau \\ Kampus II Pekanbaru, Indonesia \\ e-mail:budiistana@umri.ac.id,abrarridwan@umri.ac.id
}

\begin{abstract}
Metal melting furnace is a device used to fuse a metal. In the world of metal furnace industry is still dominated by liquid fuel in the form of diesel or solid fuel in the form of coal. In this research the source of fuel used is waste of used oil. Used oil is a waste that is promising when in the process of becoming fuel. The purpose of this study for the optimization clicking or enhance an aluminum melting furnace and get better efficiency in terms of the manufacturing process, design, raw materials, fuel consumption, time, procedures for use. This study was conducted using an experimental method to build the furnace and burner that will be used for smelting logam.isolator used is refractory cement (TNC 16) and Glass Wool. The capacity created in this study is $10 \mathrm{~kg}$ of aluminum. In designing the software use ANSYS 12.1 to simulate the state when in operation. The furnace was tested with variable weight of aluminum to be melted: $0.5 \mathrm{~kg}, 1 \mathrm{~kg}, 0.5 \mathrm{~kg}$. Later tempratur on the furnace in measuring on the inside, the outside, cover, and fuel consumption. From the results of tests and calculations get the amount of time required for the melt of $0.5 \mathrm{~kg}, 1 \mathrm{~kg}$ and $1.5 \mathrm{~kg}$ of solid aluminum is $\pm 29-34$ minutes. The time required until the $660 \mathrm{oC}$ temprature is \pm 24 minutes. The pouring temperature of this test reaches $887 \mathrm{oC}$. Q losses are 19,48197 $\mathrm{kw}$ and the resulting heat is $128854,91 \mathrm{kj}$.
\end{abstract}

Keywords: Furnace, Aluminum, Used Oil, Burner

\section{PENDAHULUAN}

Untuk mendapatkan logam cair pasti akan dilakukan dengan menggunakan suatu tungku peleburan dimana material bahan baku dan jenis tungku yang akan digunakan harus disesuaikan dengan material yang akan dilebur. Tungku yang paling banyak digunakan dalam pengecoran logam antara lain ada empat jenis tungku yaitu jenis kupola, tungku busur listrik, tungku induksi dan tungku crucible.

Industri logam khususnya pengecoran logam mempunyai peranan yang sangat penting dalam pembangunan saat ini. Untuk mewujudkan hal tersebut maka diperlukan sebuah tungku untuk proses peleburan logam non ferrous khususnya aluminium.

Aluminium adalah salah satu logam yang punya manfaat yang luas dalam kehidupan kita. Beberapa hal mulai dari hal-hal kecil sehari-hari, industri rumah tangga, dan hingga industri besar banyak memanfaatkan logam berwarna silver ini

Aluminium dapat digunakan dalam banyak hal seperti digunakan dalam alat rumah tangga, badan pesawat terbang, alat medis dan otomotif. Aluminium dapat juga dibentuk menjadi lembaran, ditarik menjadi kawat dan diekstrusi menjadi batangan dengan bermacam-macam penampang.

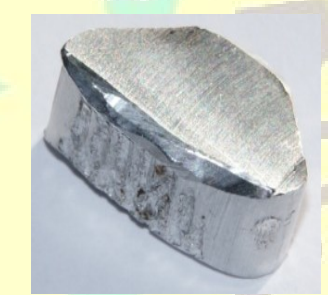

\section{Gambar 1. Aluminium}

Oli bekas sering kali di abaikan penanganannya setelah tidak bisa digunakan kembali. Padahal, jika asal dibuang dapat menambah pencemaran di bumi kita yang sudah banyak tercemar.Jumlah oli bekas yang dihasilkan pastinya sangat besar. Bahaya dari pembuangan oli bekas sembarangan memiliki efek yang lebih buruk daripada efek tumpahan minyak mentah biasa.

Ditinjau dari komposisi kimianya sendiri, oli adalah campuran dari hidrokarbon kental ditambah berbagai bahan kimia aditif. Oli bekas lebih dari itu, dalam oli bekas terkandung sejumlah sisa hasil pembakaran yang bersifat asam dan korosif, deposit, dan logam berat yang bersifat karsinogenik

Berdasarkan kriteria limbah yang dikeluarkan oleh Kementrian Lingkungan Hidup, 
oli bekas termasuk kategori limbah B3. Meski oli bekas masih bisa dimanfaatkan, bila tidak dikelola dengan baik, ia bisa membahayakan lingkungan.

Syamsuddin (2012) lebih dulu melakukan penelitian dengan judul "Perancangan Dan Pembuatan Tungku Crucible Kaleng Aluminium Kapasitas $2 \mathrm{Kg}$ Berbahan Bakar Arang Tempurung Kelapa". Tungku yang digunakan berjenis Crusible yang menggunakan hembusan udara dari blower dengan dimensi tungku yang cukup besar yaitu diameter $0,4 \mathrm{~m}$ dan tinggi 0,65 $\mathrm{m}$.

Muqofin (2015) "Rancang Bangun Tungku Pengecoran Logam Aluminium Kapasitas $10 \mathrm{Kg}$ Berbahan Bakar Limbah Oli Skala Laboratorium". Tungku yang digunakan berjenis Crusible yang menggunakan burner dengan udara bertekanan yang diperoleh dari kompresor dengan dimensi tungku diameter $0,25 \mathrm{~m}$ dan tinggi $0,4 \mathrm{~m}$.

Maka melihat kesempatan ini dilakukan penelitian melakukan optimasi dari segi desain, cara kerja dan bahan baku agar mendapatkan hasil yang lebih efisien dibandingkan peneliti sebelumnya. Tujuan penelitian ini ialah mengoptimal kan desain tungku yang sudah ada agar mendapat nilai efisiensi yang lebih tinggi dan pemanfaatan limbah baik itu logaam aluminium mau pun oli bekas.

\section{METODOLOGI PENELITIAN}

Metode yang dilakukan ialah metode eksperimental, dengan membangun tungku pengecoran logam menggunakan dua lapis isolator semen tahan api dan glass wol. Burner juga di buat untuk penyalur panas kedalam tungku. Simulasi thermal dilakukan untuk mengetahui tempratur dalam perancangan menggunakan software ansys 12.1. Pengujian dilakukan dengan variabel berat logam aluminium yang sudah ditentukan yaitu $0,5 \mathrm{~kg}, 1$ $\mathrm{kg}$, dan $1,5 \mathrm{~kg}$.

\section{Alat dan Bahan}

Menyiapkan alat dan bahan dlam penelitian ini. Dan alat alat utama yang digunakan adalah:

\section{Gerinda tangan}

2. Mesin cutting

3. Sendok semen

4. Bor tangan

5. Mesin rolling

6. Mesin las

7. Alat ukur

Dan bahan yang digunakan adalah:

1. Semen tahan api ( TNC 16 )

2. Pelat baja

3. Blower

4. Glass Wol

5. Selang

6. Pipa Baja

\section{Diagram Alir Penelitian}

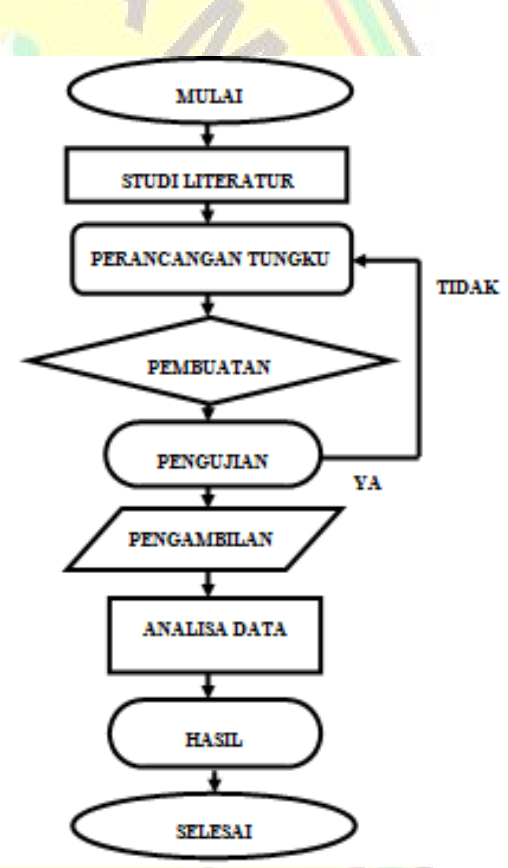

Gambar 2. Diagram Alir Penelitian

Pembuatan Tungku

Langkah awal dalam pembuatan tungku yaitu dilakukan simulasi termal dengan menggunakan software ansys 12.1 dimana tungku di desain dalam dalam bentuk silinder dengan dua lapisan isolator semen tahan api dan Glass wol. Tempratur dalam tungku di berikan hingga $750^{\circ} \mathrm{C}$. 


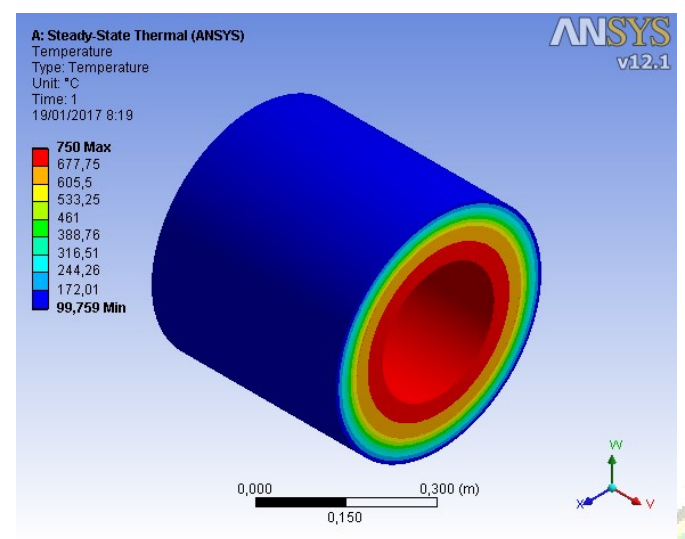

Gambar 3. Simulasi Thermal Ansys 12.1

Dan setelah beberapa kali dilakukan simulasi di dapatkan ukuran ketebalan ideal isolator yaitu $5 \mathrm{~cm}$ untuk semen tahan api (TNC 16) dan $5 \mathrm{~cm}$ untuk Glass wol.

Dengan diketahui ukuran ketebalan isolator yang diinginkan maka langkah berikutnya memberikan beberapa ukuran acuan yang disesuaikan dengan kapasitas tungku yaitu $10 \mathrm{~kg}$. Diameter Tungku: 0,38 m, Diameter dalam cawan: 0,16 m, Ketebalan cawan: 0,005 m, Ketebalan tutup tungku: 0,06, dan Diameter lubang kontrol: $0,08 \mathrm{~m}$.

Ukuran lainnya didapatkan dengan menggunakan persamaan silinder sehingga dapat diketahui ketinggian ruang bakar dan ketinggian ruang cawan, $35 \mathrm{~cm}$ untuk ruang bakar, $25,5 \mathrm{~cm}$ untuk tuang cawan dan toleransi jarak antara dinding dalam tungku dan dinding luar cawan sebesar $4,5 \mathrm{~cm}$.

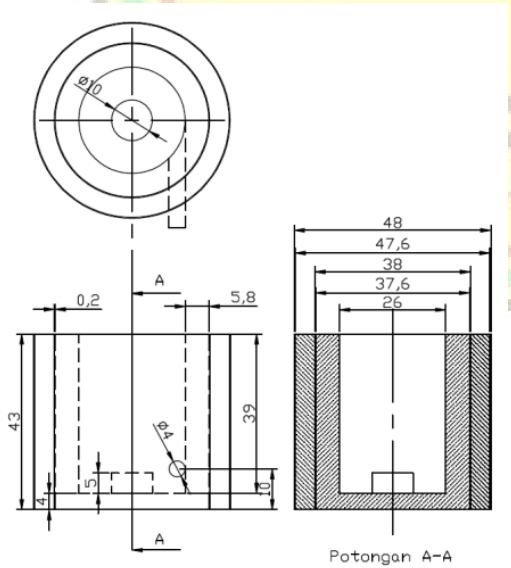

Gambar 4. Desain Badan Tungku

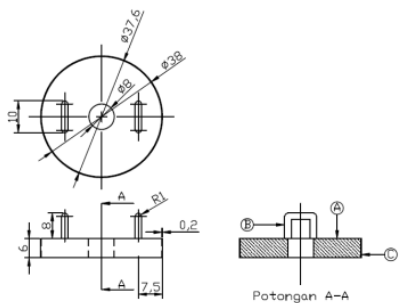

Gambar 5. Desain Tutup Tungku

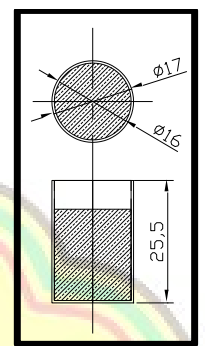

Gambar 6. Desain Cawan

Setelah didapatkan ukuran desian tungku yang akan di buat maka selanjutnya dilakukan proses manufaktur. Dengan menggunakan mesin rolling plat baja di buat sesuai ukuran dan di isi dengan seman tahan api (TNC 16) dengan pebandingan yang sudah ditentukan.

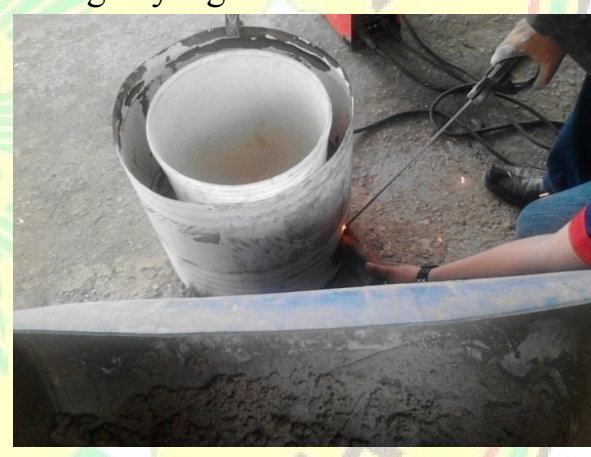

Gambar 7. Pengelasan Tungku

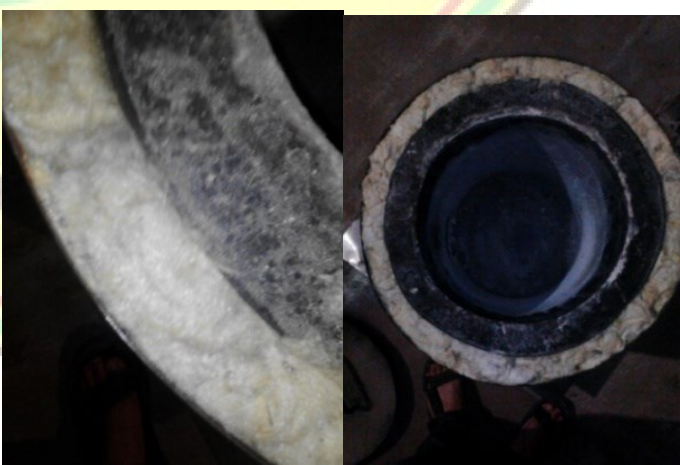

Gambar 8. Isolator Tungku 


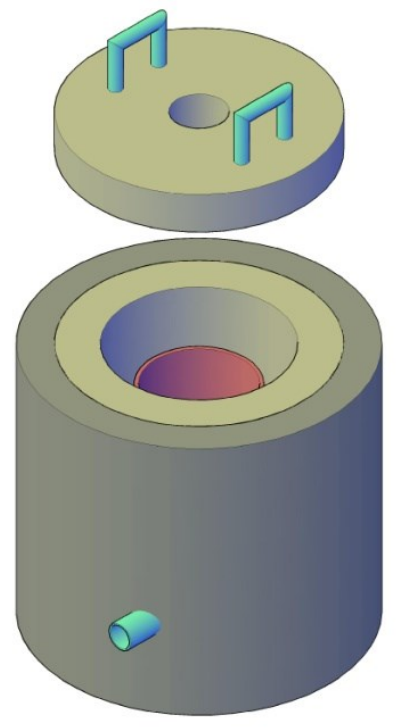

Gambar 9. Desain 3D Tungku

Alat Pemanas ( Burner ) ini berfungsi sebagai sumber panas dalam pengecoran logam ini. Alat Pemanas (Burner ) ini harus di letakan pada posisi yang tepat ditungku agar panas yang dikeluarkan bisa didistribusikan secara merata. Alat pemanas ( Burner) menggunakan bahan bakar limbah oli bekas

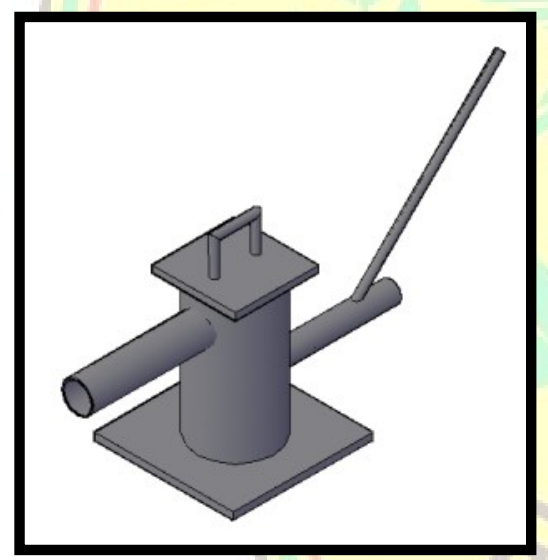

Gambar 10. Desain 3D Burner

Kelebihan dari Desain burner ini adalah dapat menghasilkan nyala api yang besar dan lebih hemat karena udara disuplai dari Blower bukan Kompressor selain itu burner dapat membakar dengan lebih bersih dan sempurna karna tidak ada oli yang akan berceceran.

\section{HASIL DAN PEMBAHASAN}

Dari hasil pengujian tungku dengan 3 variabel berat alumunium yang dileburkan yaitu $0,5 \mathrm{~kg}, 1 \mathrm{~kg}$, dan 1,5 kg didapatkan hasil berupa grafik tempratur dan konsumsi bahan bakar.
Pengujian dilakukan dihari yang sama dengan interval 1 jam setiap pengujiannya. Dan berikut adalah datanya:

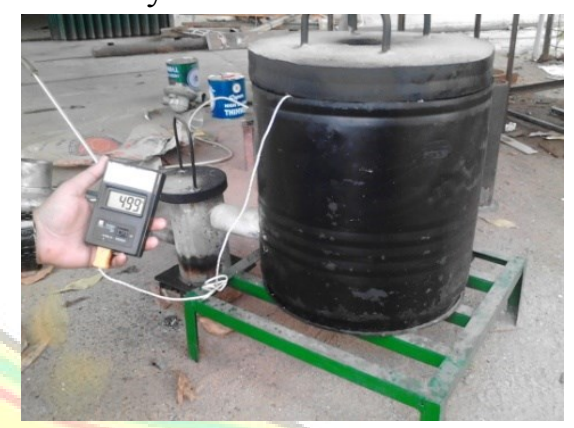

\section{Gambar 11. Pengujian Tungku}

Hasil Pengujian 0,5 Kg

Pada pengujian pertama dilakukan peleburan alumunium dengan berat $0,5 \mathrm{~kg}$ alumunium. Dan berikut adalah grafik distribusi temparatur dan konsumsi bahan bakar pada pengujian tersebut.

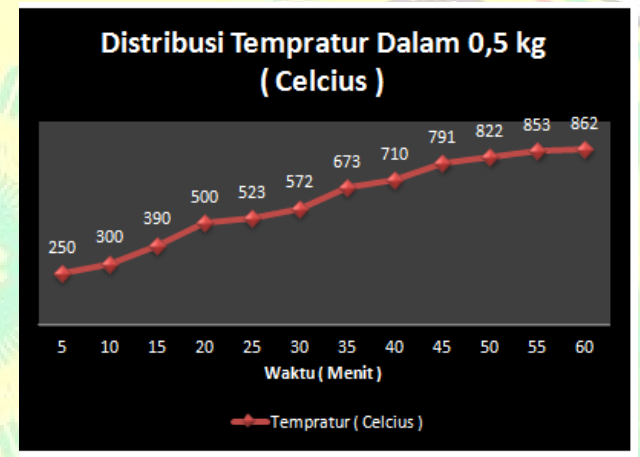

Gambar 12. Grafik Distribusi Tempratur Dalam 0,5 kg Alumunium

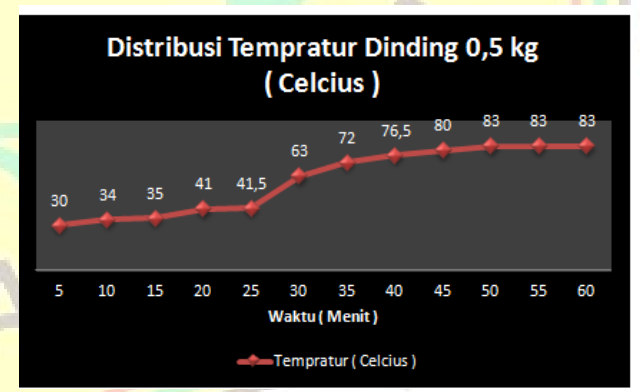

Gambar 13. Grafik Distribusi Tempratur Dinding 0,5 kg Alumunium

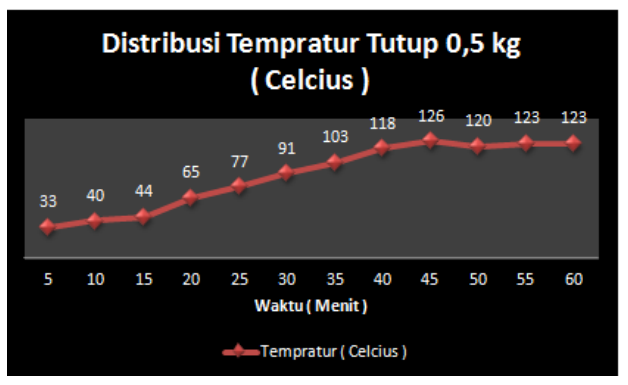


Gambar 14. Grafik Distribusi Tempratur Tutup 0,5 kg Alumunium

Bahan bakar mengalir dengan konstan, bahan bakar awal dalam wadah bahan bakar adalah 2 liter.

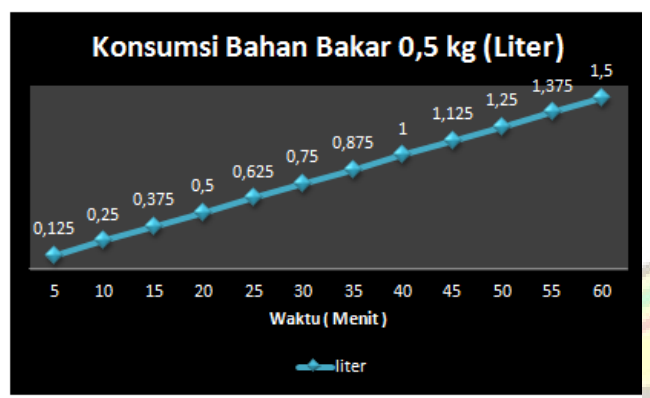

Gambar 15. Grafik Distribusi Bahan Bakar 0,5 kg Alumunium

Dari grafik tempratur dan konsumsi bahan bakar pengujian pertama belum terlalu optimal pada tempratur akhir baik dari waktu dan cukup banyak bahan bakar yang di gunakan, hal ini dikarenakan kondisi dari burner yang masih dingin dimulai dari tempratur kamar. Alumunium mencair pada waktu 34 menit dan menghabiskan bahan bakar 1,5 liter.

3.2 Hasil Pengujian $1 \mathrm{Kg}$

Pada pengujian kedua peleburan alumunium dilakukan dengan berat $1 \mathrm{~kg}$ alumunium. Dan berikut adalah grafik distribusi temparatur dan konsumsi bahan bakar pada pengujian tersebut.

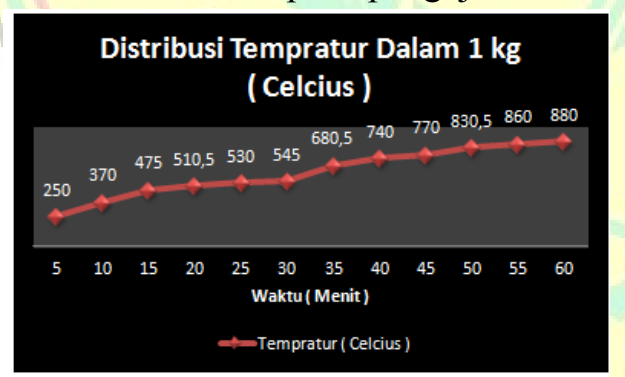

Gambar 16. Grafik Distribusi Tempratur Dalam 1 kg Alumunium

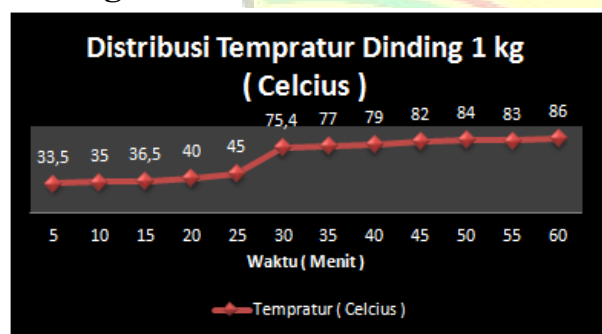

Gambar 17. Grafik Distribusi Tempratur Dinding $1 \mathrm{~kg}$ Alumunium

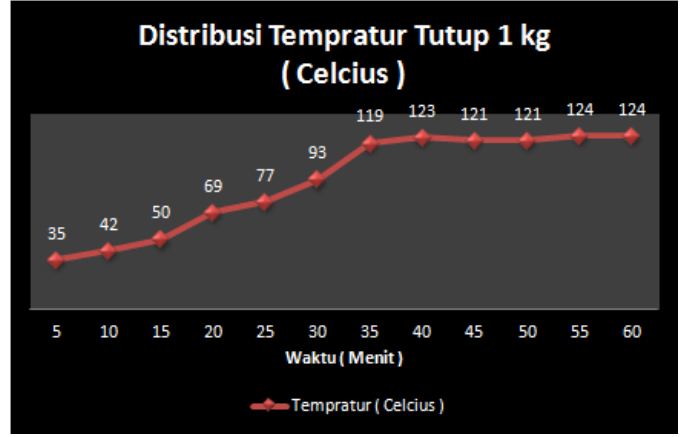

Gambar 18. Grafik Distribusi Tempratur Dinding 1 kg Alumunium

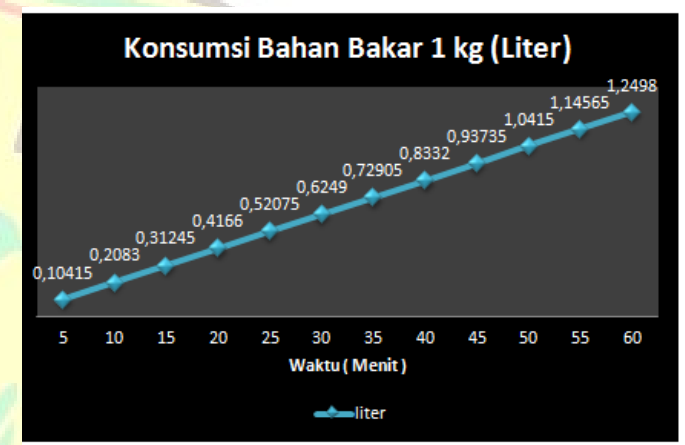

Gambar 19. Grafik Distribusi Bahan Bakar 1 kg Alumunium

Dari grafik tempratur dan konsumsi bahan bakar pengujian kedua distribusi tempratur dan penggunaan bahan bakar sudah mulai stabil. Alumunium mencair pada waktu 32 menit dan menghabiskan bahan bakar 1,3 liter.

\subsection{Hasil Pengujian 1,5}

Pada pengujian ketiga peleburan alumunium dilakukan dengan berat $1,5 \mathrm{~kg}$. Dan berikut adalah grafik distribusi temparatur dan konsumsi bahan bakar pada pengujian tersebut.

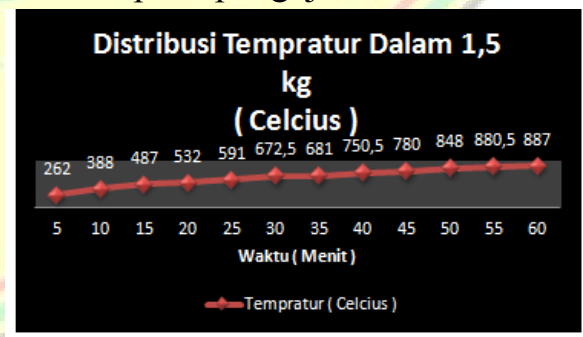

Gambar 20. Grafik Distribusi Tempratur Dalam 1,5 kg Alumunium 


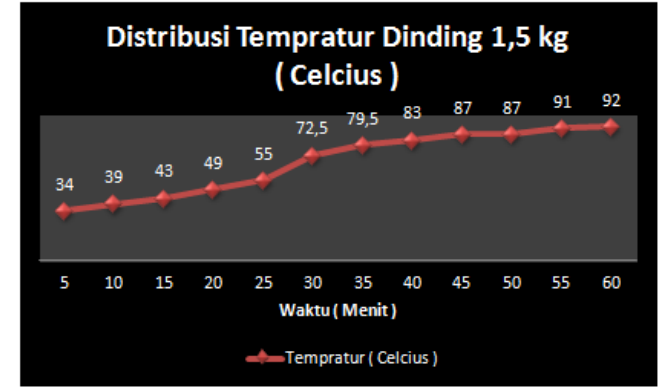

Gambar 21. Grafik Distribusi Tempratur Dinding 1,5 kg Alumunium

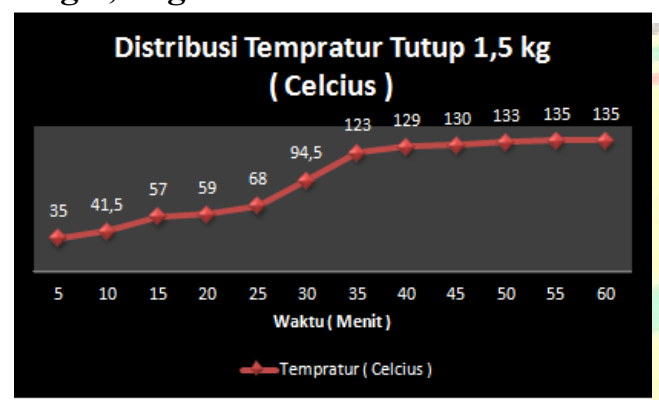

Gambar 22. Grafik Distribusi Tempratur Tutup 1,5 kg Alumunium

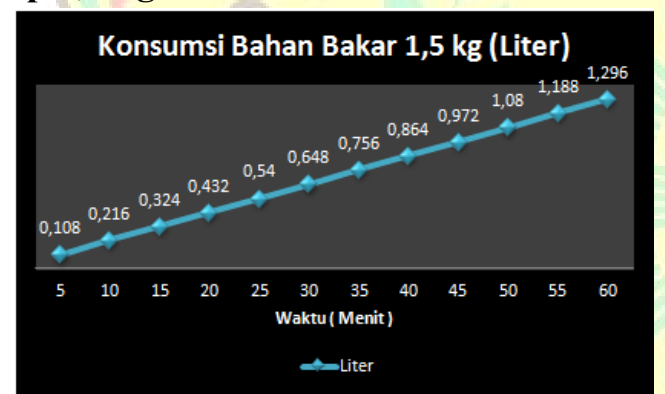

Gambar 23. Grafik Distribusi Bahan

\section{Bakar 1,5 kg Alumunium}

Dari grafik tempratur dan konsumsi bahan bakar pengujian kedua distribusi tempratur dan penggunaan bahan bakar sudah mulai stabil hal ini di karena kan proses pembakaran pada burner yang lebih stabil. Alumunium mencair pada waktu 29 menit dan menghabiskan bahan bakar 1,3 liter.

Tabel 1. Hasil Data Pengujian

\begin{tabular}{|c|c|c|c|c|c|}
\hline No & $\begin{array}{c}\text { JENIS } \\
\text { BAHAN } \\
\text { BAKAR }\end{array}$ & $\begin{array}{c}\text { JUMIAH } \\
\text { ALUMUNIUM } \\
\text { YANG } \\
\text { DILBURKAN } \\
(\mathrm{Kg})\end{array}$ & $\begin{array}{c}\text { TITIK } \\
\text { LEBUR } \\
\left({ }^{\circ} \mathrm{C}\right)\end{array}$ & $\begin{array}{c}\text { LAMA } \\
\text { PROSES } \\
\text { PELEBURAN } \\
\text { ( MENIT ) }\end{array}$ & \begin{tabular}{|l} 
JUMLAH \\
PEMAKALAN \\
BAHAN \\
BAKAR \\
(Liter )
\end{tabular} \\
\hline 1 & $\begin{array}{c}\text { Oli } \\
\text { Bekas }\end{array}$ & 0,5 & 669 & 34 & 1,5 \\
\hline 2 & $\begin{array}{c}\text { Oli } \\
\text { Bekas }\end{array}$ & 1 & 671 & 32 & 1,25 \\
\hline 3 & $\begin{array}{l}\text { Oli } \\
\text { Bekas }\end{array}$ & 1,5 & 672 & 29 & 1,3 \\
\hline
\end{tabular}

\section{KESIMPULAN}

Dari hasil pengujian dan analisis data dapat disimpulkan beberapa hal sebagai berikut:

1. Tungku peleburan berbentuk silinder yang terbuat dari plat baja

2. Dimensi luar Diameter $48 \mathrm{~cm}$ tinggi $43 \mathrm{~cm}$.

3. Dimensi dalam (krusibel) diameter $26 \mathrm{~cm}$ dan tinggi $39 \mathrm{~cm}$

4. Isolator dinding tungku dibuat dengan menggunakan bahan refractory semen tahan api yang memiliki kemampuan tahan terhadap panas hingga $1600^{\circ} \mathrm{C}$ dan Glass wool yang memiliki nilai konduktivitas termal $0,038 \mathrm{~W} / \mathrm{m} .{ }^{\circ} \mathrm{C}$

5. Efisiensi yang di dapatkan dengan penambahan isolator glass wol lebih dari $200 \%$

6. Bahan bakar yang digunakan adalah oli bekas

7. Jumlah waktu yang dibutuhkan untuk melebur $0,5,1$, dan $1,5 \mathrm{~kg}$ alumunium padat adalah \pm 29 - 34 menit.

8. Waktu yang dibutuhkan hingga tempratur $660^{\circ} \mathrm{C}$ adalah \pm 24 menit

9. Tempratur tuang dari pengujian ini mencapai $887^{\circ} \mathrm{C}$.

10. Nilai Q losses adalah $19,48197 \mathrm{kw}$

11. Kalor yang dihasilkan adalah $128854,91 \mathrm{kj}$

12. Pada saat pengujian faktor cuaca dan frekuensi pemakaian alat mempengaruhi waktu peleburan dan konsumsi bahan bakar.

13. Dari keseluruhan hasil pengujian dan analisa alat ini berhasil mecapai tujuan untuk menjadi lebih efisien dari sebelumnya baik dari segi konsumsi bahan bakar dan waktu peleburan.

\section{DAFTAR PUSTAKA}

Bramanta. 2008. Rancangan Dapur Peleburan Aluminium Kapasitas $30 \mathrm{Kg}$. Departemen Teknik Mesin. Universitas Sumatera Utara, Medan

B.Istana; J.Lukman. Rancang Bangun dan Pengujian Tungku Peleburan Aluminium Berbahan Bakar Minyak Bekas. Surya Teknika, Vol. 2, No.4, Desember 2016: 10-14. Teknik Mesin Universitas Muhammadiyah Riau 
Holman, J.P. "Perpindahan Kalor", Erlangga, Jakarta, 1986.

Magga, R. 2010. Analisis Perancangan Tungku Pengecoran Logam (Non-Fero) Sebagai Sarana Pembelajaran Teknik Pengecoran. Jimt, Vol. 7, No.1, Mei 2010: 54 -60. Teknik Mesin Universitas Tadulako.

Muqofin. 2015. Rancang Bangun Tungku Pengecoran Logam Aluminium Kapasitas $10 \mathrm{Kg}$ Berbahan Bakar Limbah Oli Skala Laboratorium. Skripsi. Universitas Muhammadiyah Riau. Pekanbaru

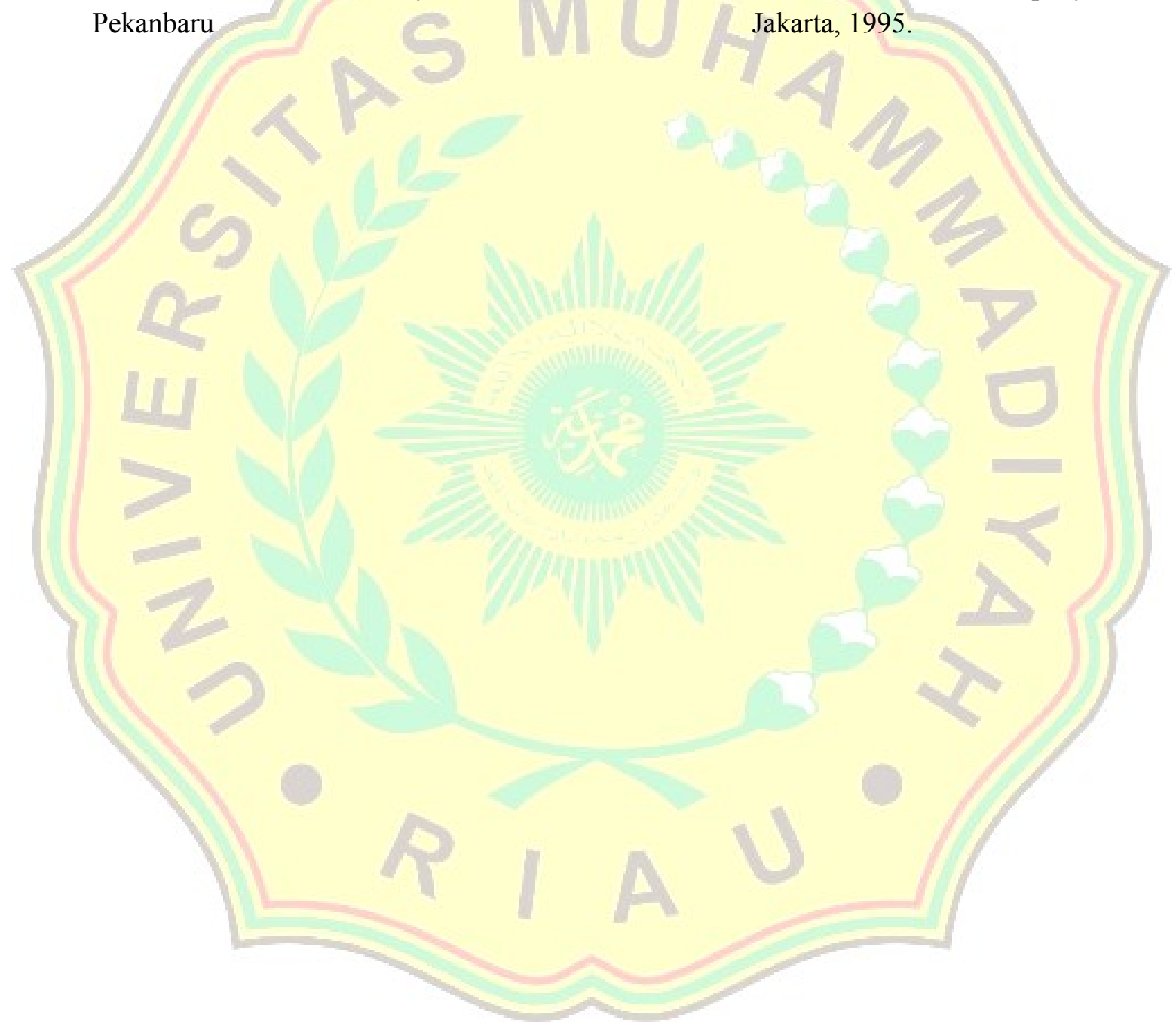

Pratomo, A, W. 2012. Rancang Bangun Burner Berbahan Bakar Oli Bekas Untuk Pengecoran Kuningan. Semarang. Vol 6. Hal 112-115. Jurnal Rekayasa Mesin Politeknik Negeri Semarang.

Syamsuddin. 2012. Perancangan Dan Pembuatan Tungku Crucible Kaleng Aluminium Kapasitas $2 \mathrm{Kg}$ Berbahan Bakar Arang Tempurung Kelapa. Departemen Teknik Mesin Universitas Riau. Pekanbaru

Tata Surdia, Shinroku Saito, "Pengetahuan Bahan Teknik", Pt. Prapadya Paramita, Jakarta, 1995. 